\title{
Documentation Required for Accreditation of Medical Testing Laboratories with Special Reference to National Accreditation Board for Testing and Calibration of Laboratories
}

\author{
Thekkuttuparambil Ananthanarayanan Ajith* \\ Department of Biochemistry, Amala Institute of Medical Sciences, Amala Nagar, Thrissur-680 555, Kerala, \\ India. \\ *Corresponding Authors: Thekkuttuparambil Ananthanarayanan Ajith, Department of Biochemistry, \\ Amala Institute of Medical Sciences, Amala Nagar, Thrissur-680 555, Kerala, India.
}

\begin{abstract}
Medical testing laboratories are undergoing accreditation to cope with the international standards. During the last decade, there was a significant increase in the number of medical testing laboratories undergoing accreditation procedures. In India, National Accreditation Board for testing and calibration of Laboratories (NABL) and National Accreditation Board for Hospital and health care providers (NABH) are two autonomous bodies under Quality Council of India (QCI) conducting onsite assessment to grand accreditation. The onsite assessment is focused on the technical competency and supportive evidences of documentation against the implementation of standards prescribed by International Organization for Standardization 15189:2012. Despite the necessary training on the standards, many laboratory people are not aware about the details that must be included while preparing various registers as supportive documents. This emphasizes the need for an article to highlight the essential details that must be incorporated while preparing documents. This review article discusses the preparation of documentation necessary for NABL accreditation programme for medical testing laboratories.
\end{abstract}

Keywords: Accreditation, competency, documentation, health care providers, laboratories, laboratory quality management system, Quality control, register

\section{INTRODUCTION}

Accreditation of a lab is the formal recognition of its competency, capability and credibility to do the prescribed task by a third party [1]. It improves the quality of the testing laboratory which indicates that the test results meet the need and expectations of client (patient, doctor or insurance agency). This improves the client's confidence on the test reports issued by such laboratory. In India, National Accreditation Board for testing and calibration of Laboratories (NABL) and National Accreditation Board for Hospital and health care providers (NABH) are two autonomous bodies under Quality Council of India (QCI) create and evaluate the standards for recognition of medical testing laboratories. The requirements for quality and competence for medical testing laboratories are adopted from the standards prescribed by International Organization for Standardization (ISO) 15189:2012 $[2,3]$.

NABL is a signatory to Asia Pacific Accreditation Cooperation (APAC) and International Laboratory Accreditation Co-operation (ILAC) through mutual recognition arrangements $[4,5]$. The test results issued by an accredited lab will be accepted by customers in all the mutual recognition arrangements partner countries. Though both bodies cover the standards necessary for the medical laboratories, NABL specifies the detailed assessment of laboratory with standards described under management system requirements and technical requirements. Whereas in the NABH, the standards for laboratory are prescribed under Access Assessment and Continuity of Care 6, 7 and 8 in chapter 1 [6]. Despite Quality Assurance Scheme for Basic Composite Medical Laboratories (Entry Level) is available for a specified scope of test in basic medical laboratories, it has not approved by APAC and ILAC [7]. Though the necessary training on the NABL standards and for internal auditing offered by agencies under National Board for Quality Promotion, QCI, the trainees are facing difficulties or creates errors whiling documenting the evidences of implemented standards. Therefore, an article describing about the necessary documentation and details of each will be worthwhile to people preparing for 
Documentation Required for Accreditation of Medical Testing Laboratories with Special Reference to National Accreditation Board for Testing and Calibration of Laboratories

accreditation. This review article covers the details and list of documents needed for NABL accreditation of medical testing lab.

\section{DoCUMENT FOR QUALITY POLICY}

Quality manual (QM) is the master document describes various quality policies available in the laboratory service to meet the customer's satisfaction as per the ISO 15189:2012 requirements that followed in the recent edition of the NABL112 guidelines [4]. QM is usually prepared by quality manager, who had undergone training conducted by various agencies accredited to National Board for Quality Promotion under QCI. Instruction for QM preparation has been provided in the NABL 160 brochure [8]. The lab director, a person with well-defined duties and have expertise about the ISO 15189:2012 standards, will approve and issue the manual. A structure of QM which includes document's title and affiliation, issue no, issue date, copy no, holders' name and name of person issued on the cover page (page 1), details of release authorization provide in page 2 with a statement of authorization, page 3 contains details for amendment as table, page 4 contains the distribution list of the manual, page 5 carries the table of content and page 6 is for glossary of terms (abbreviation).

Quality policy, a statement covers vision and mission with objectives of lab service, will be included in the page 5 of the QM. The other pages of QM, in section wise, should describe the policies against all applicable elements of ISO 15189:2012 (NABL 112) in a simple language which is understandable to all lab personnel. All the pages of the manual, after the content pages, should be arranged with detail such as lab name, document's title, section, section wise parts per page in the header and details such as designation of the person prepared, approved and issued the document with sign, details of amendment such as date and page no of amendment, signature of person who made the amendment and page number in the footer of the page. Each amendment should be approved by the lab director with signature and purpose of the amendment added in the amendment table. The same should be evidenced in the appropriate page of the manual. It is compulsory that a copy of QM which is issued to the lab was read and understood by lab personnel during their induction training programme. A certificate should be maintained with name and signature of each lab personnel to support the evidence that the QM distributed among the lab personnel was read and understood. The necessary management system (secondary level documents) for each policy should be cross referred in the QM. Every document should have a title with unique ID number.

Table1. List and details of major registers and forms required for lab accreditation.

\begin{tabular}{|l|l|}
\hline SNO. & Registers \\
\hline 1 & Access control register (serial no, name, date and time and signature) \\
\hline 2 & $\begin{array}{l}\text { Equipment register (serial no, unique ID no, date of purchase, date of placement into service, calibration } \\
\text { status, Contact person for maintenance and repair -telephone number as appropriate). }\end{array}$ \\
\hline 3 & Equipment maintenance registers (I.e. daily, weekly, monthly, annually..........). \\
\hline 5 & Equipment down time register (unique ID no, date of breakdown, date of repair and placement into service). \\
\hline 6 & $\begin{array}{l}\text { Certificate of instrument calibration (details as per the manufacture's instruction). } \\
\text { profile and certificate of authorized signature. }\end{array}$ \\
\hline 8 & $\begin{array}{l}\text { Authorized signatories, if applicable, to report results including critical care results......(Authorization letter } \\
\text { issued to person) }\end{array}$ \\
\hline 9 & $\begin{array}{l}\text { Training registers (Induction and periodic- for MSDS, safety, communication skill, operating equipments, } \\
\text { critical test results, phlebotomy). Reg. should contain details of topics, name of trainer, date and venue of } \\
\text { training, attendance of participants. }\end{array}$ \\
\hline $\begin{array}{l}\text { Sample collection registers } \\
\text { a) Primary collection centre: Patients ID; test requested; sample collected date, time with name and sign of } \\
\text { lab personnel who collected the sample; sample discarded date and time with name and sign of personnel } \\
\text { who discarded the sample. } \\
\text { b) Collection centre: Sample receiving time at main lab sample receiving area as additional details to above } \\
\text { register. } \\
\text { c)Referral lab: Patients ID, tests name, date and time of sample collection, name and sign who collected the } \\
\text { sample, name of person who receives the sample for transportation with sign, date and time, date /time of } \\
\text { results received with name and sign. }\end{array}$ \\
\begin{tabular}{l} 
Sample rejection register (Patients ID, test name; Date and time of collection, Name and sign who collected \\
\hline 10
\end{tabular} \\
\hline 5
\end{tabular}


Documentation Required for Accreditation of Medical Testing Laboratories with Special Reference to National Accreditation Board for Testing and Calibration of Laboratories

\begin{tabular}{|c|c|}
\hline & $\begin{array}{l}\text { the sample, date and time of rejection with reason, details of customer informed, Name and sign of person } \\
\text { who informed the customer); calculate \% rejection. }\end{array}$ \\
\hline 11 & $\begin{array}{l}\text { Critical test reporting register (for tests results from referral lab and in-house) } \\
\text { (copy of tests results from referral lab should be maintained) } \\
\text { i.e. Patients ID, Date and time of sample collection with name and sign, sample receipt in central lab with } \\
\text { name with sign-in case of sample from collection centre, test name, results, reporting time plus reporting } \\
\text { methods, name with sign who reports the result. }\end{array}$ \\
\hline 12 & Re-do reg. [Patients ID, Date, initial value, final value, name and sign, calculate monthly freq \%] \\
\hline 13 & Inventory control register (i.e. register of external purchase) \\
\hline 14 & $\begin{array}{l}\text { Internal QC (Lot no. of QC, date and time, test, interpretation, rule of rejection applied-if applicable, route } \\
\text { cause analysis-if needed, monthly CV\% of each parameter, measurement of uncertainty, name with sign of } \\
\text { quality manager). } \\
\text { For AFB: both +ve and -ve control needed with date and time, results, interpretation, name with sign of } \\
\text { quality manager. }\end{array}$ \\
\hline 15 & $\begin{array}{l}\text { Proficiency testing/EQAS (report)- Evaluation report, route cause analysis-if required, name with sign of } \\
\text { quality manager. }\end{array}$ \\
\hline 16 & Comparability of examination results between two instruments-if applicable \\
\hline 17 & $\begin{array}{l}\text { Verification of reagents (date, new batch lot no, test, result, old batch/lot no, test, result, remarks, name plus } \\
\text { sign) } \\
\text { Stains/antibiotic discs-weekly/culture medias-use ATCC strain/strips/IHC antibodies } \\
\text { (Register for validation of new method: If applicable) }\end{array}$ \\
\hline 18 & Internal audit $\quad$ (File with circular for IA, check list + Non-conformity report). \\
\hline 19 & Corrective and preventive action (on all Quality Indicators) \\
\hline 20 & Management review (minutes-should contain agenda + attendance of MR meeting). \\
\hline 21 & Register for accident/indicent reporting \\
\hline 22 & MSDS \\
\hline 23 & Compliant register \\
\hline 24 & Feedback register \\
\hline 25 & Personal evaluation from \\
\hline 26 & Vander evaluation form \\
\hline 27 & Referral lab evaluation form \\
\hline 28 & Temperature (rooms/water bath/oven/incubator) chart \\
\hline 29 & The relevant tariff list of scope of testing (should be available to patients, on request) \\
\hline 30 & AC filter cleaning chart \\
\hline 31 & Separate registers for area- furniture/floor cleaning; (Area, date plus time; name with sign) \\
\hline 32 & Percentage adherence to safety precautions by employees working in diagnostics. \\
\hline 33 & $\begin{array}{l}\text { Percentage of reports co-relating with clinical diagnosis in Pathology report (i.e. correlation with provisional } \\
\text { diagnosis/clinical diagnosis provided in the investigation form) }\end{array}$ \\
\hline 34 & Register's register \\
\hline 35. & 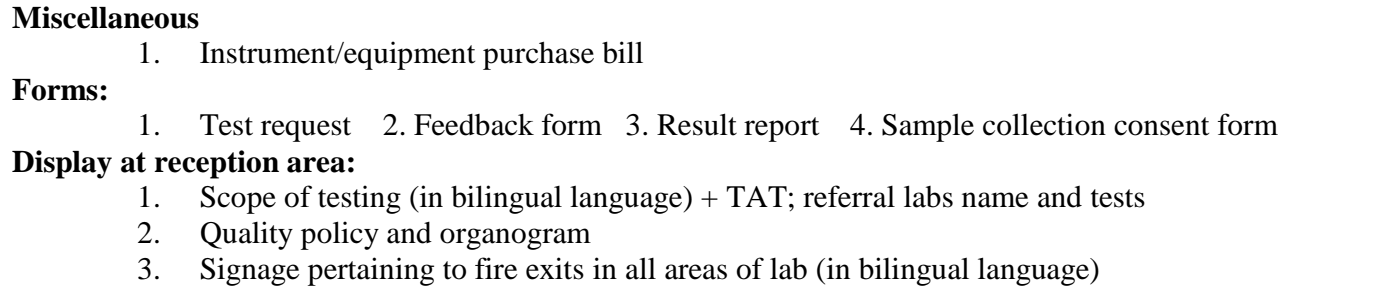 \\
\hline
\end{tabular}

P.s. The list may vary based on the requirement, discipline and service provided.

\section{Documents for Quality Management System Procedure And Manuals}

The main documents that support the management system procedure are quality system procedure (QSP) and standard operating procedure (SOP). While other level of documents are manuals like sample collection and waste disposal manual, Turn-Around-Time (TAT) manual and safety manuals which are also a part of quality management system (Figure 1). QSP is for describing all the quality associated procedures including procedure for equipment purchase, calibration and maintenance, selection of referral lab, external procurements and purchase, internal quality control (IQC), Proficiency Testing/External Quality Assurance Service (EQAS), collection of feedback and 
compliant, corrective and preventive action, revision of all documents, selection of staff and training, evaluation staff and training (for competency and skill), internal audit, document control, advisory services etc. While SOP describes the standard procedures used for testing the parameters under the scope of testing. SOP for scope of testing should be prepared according to standard procedures (kit insert, procedure provided in scientific journals or methods given in text books) with citation of reference. The method developed in in-house should be validated for its linearity, cross reactivity, specificity, sensitivity and detection limit. The recent NABL criteria indicate that the kit insert shall not replace the SOP [3].The sample collection manual should contain specimen collection procedures in the lab under the scope of testing. There should be detailed procedure available for the sample rejection criteria too. This manual can be integrated with the details of bio-medical waste disposal procedures which should be prepared according to the recent rules and regulations [9]. In case of NABH accreditation, the safety manual should be integrated with the hospital safety manual. It should explain the details of safety aspects while handling the biohazards during the laboratory practice. The TAT manual depicts the time elapsed between the sample collection to result generation of each test under the scope of testing. The validity of all these documents should be clearly indicated in the policy of QM. During this period, amendments can be made wherever necessary. The other level of documents such as registers and forms should be cross referred in the QSP and manuals wherever necessary.

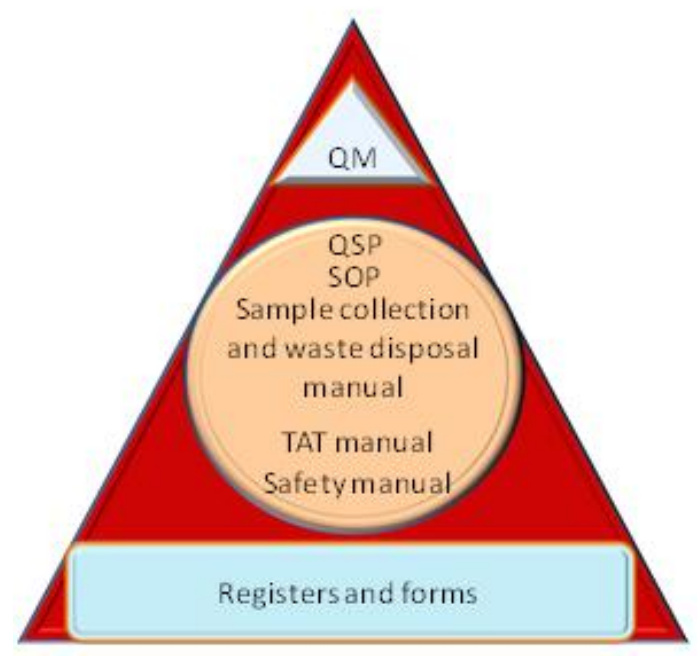

Figure1. List of main level documents required to cover the quality policy and procedure. QM: quality manual; QSP: quality system procedure; SOP: standard operating procedure; TAT: Turn-Around-Time.

\subsection{Documentation of Pre-Analytical Phase}

The documents such as registers for sample collection, rejection, details of sample transported to inhouse and to referral lab etc. are authorized and issued by the authorized person with signature in the first inner page. Details of the registers needed in the lab are depicted in table 1. Each register should be designed to fulfill the quality requirement without errors. For example, a sample collection register should contain the details about the patients ID, sample collected date and time, sample received time at the lab sample collection area (in case of sample collected at station other than the primary sample collection area of the lab), test requested and sample discarded date and time. These details should be supported with necessary sign of the lab personnel where ever necessary.

A separate sample collection register is needed for sending sample to referral labs. The reagents and equipment register need to maintain with details. All equipment must be labeled with a unique ID no, calibration details and contact number of person (in case of breakdown). The equipment register should contain the same details along with calibration due date, year of purchase, serial/model number and lab personnel trained to operate them. A separate maintenance register should be kept for daily, weekly and monthly maintenance as applicable. A sample rejection register should kept with details of sample ID, date and time of rejection, reason for rejection as well as the name and sign of the lab personnel who reported the rejection of sample to client should be evidenced. Register is also needed to keep the entire equipment calibration certificate. 
Register for lab personnel should contain the details of personnel profile including qualification, experience, appointment date with copy of appointment order, job duties and responsibilities, training undergone, periodic evaluation on the knowledge, skill, attitude and communication and vaccination status. Laboratory operating in shifts should clearly provide the staff working in each shift. Certificate should be made available to all the staffs competent to report, review and authorization of results (Signing of test reports) [10]. Register for temperature monitoring of sample collection and processing room/incubator/refrigerator/cold lab/wax melting bath/slide warming stage etc. should be kept. Register for periodic cleaning of phlebotomy area and surfaces of work bench, daily discarding the liquid waste from analyzers etc. should be maintained. It is the duty of the technical manager and quality manager to verify the up to date maintenance of registers. An access control register is needed to record entry of persons to lab who are normally not allowed.

\subsection{Documentation of Analytical Phase}

Detail of internal quality control (IQC) with rules applied (Biochemistry and Hematology lab), sample repeatability, sample redo, critical test reporting (in-house and out sourced tests), instrument beak down time are the major registers in this phase. The results of the external quality assurance service (EQAS) or inter-laboratory comparison should be filed properly. The route cause analysis of the report, if needed, can be maintained along with the EQAS report. In case of IQC, if data are stored in the analyzer, a register should contain the daily decision on the IQC data with monthly \% coefficient of variation $(\mathrm{CV})$ value. Measurement of uncertainty of control value should be provided in the same register as per the recent NABL112 criteria [3]. The register for IQC in Cytopathology/ Histopathology should contain the report of all personnel who cross-checked the sample with remarks, if any. Assays where there is with no provision for EQAS or inter-laboratory comparison, a register for split sample testing should be maintained. The test report in the prescribed format should be maintained as soft copy/hard copy for a defined period. In case of results received from the referral lab, a hard/soft copy of the same should be maintained in the lab. Registers for antibiotic disc testing, stain verification, kit verification, results comparison from identical analyzers, sterilization status (chemical or biological test) of the autoclave, colony count from biologic safety cabinet and its annual certification, colony count from the autoclave for sample discarding etc. are needed. In Cytopathology/Histopathology lab, register for formalin fume monitoring is needed.

\subsection{Documentation of Post-Analytical Phase}

Registers are required for sample discarding (can be integrated with the sample collection register), feedback and complaint. In case of complaint received from the customer or lab personnel, the register should contain the details of decision taken and date and time of intimation of the decision to the concerned person, if needed. Wherever the route cause analysis required on quality indicators like complaint, IQC, EQAS, instrument break down time etc. provision should be given in the register for periodic review of the decision implemented. Registers for purchase order, housekeeping, stock, periodic cleaning of $\mathrm{A} / \mathrm{C}$ filters, testing of drinking water, monitoring of TAT, accident/incident report, internal audit report (non-conformity report with plan/check list) and management review meeting minutes are also needed in the appropriate format. The agenda of the management review meeting should highlight the discussion on the previous review meeting minutes and all quality indicators available as given in the audit report. The meeting minutes should be circulated among the laboratory personnel. Hence, a meeting minutes copy containing signature of all lab personnel should be maintained. All the documents are controlled with a master register for their traceability which contains the details of title and unique ID of all documents. A well-defined policy should be implemented to keep all the documents for the defined time. Several forms such as indent form (purchase requisition), test request form, test reporting form, complaint form, feedback form, vendor evaluation form, staff evaluation form, evaluation form for referral lab, material safety data sheet are also needed. The retention time of these registers is usually 1 year and can be marked as obsolete, once the internal auditing is over. However, policy of the lab on the retention time of registers can be followed.

\section{CONCLUSiON}

Documentation in the form of manuals, registers and forms is the essential part of the lab accreditation programme. Medical testing laboratories are following ISO 15189:2012 standards developed and implemented by two autonomous bodies, NABL and NABH under QCI, India. The procedure of 
accreditation required various documents. Though the lab personnel are aware about the primary and secondary documents, preparing the documents and maintaining them is a laborious job. Many documents are not familiar or the design of each remains a lacuna among the lab personnel. The primary level document is quality manual while the second level documents are standard operating procedure, quality system procedure, sample collection and waste disposal manual, turn-around-time manual and safety manual. All these second level documents are further supported by registers and forms.

\section{REFERENCES}

[1] Kanagasabapathy AS, Pragna Rao P. Laboratory accreditation - procedural guidelines. Indian J Clin Biochem.2005; 20 (2):186-188.

[2] Schneider F, Maurer C, Friedberg RC. International Organization for Standardization (ISO) 15189. Ann Lab Med. 2017; 37(5): 365-370.

[3] ISO 9000 (QMS) - FAQ's. Available from: http://www.bis.org.in/cert/faqmscd.htm\#9000-q1. [Last accessed on 2011 Dec 11].

[4] Specific Criteria for Accreditation of Medical Laboratories. National Accreditation Board for Testing and Calibration Laboratories 112. issue no. : 04, issue date : 11-feb-2019, amendment no. : 01, amendment date : 26-apr-2019. Available from https://nabl-india.org [Last accessed on 2020 Mar 02].

[5] About ILAC. Available from: http://www.ilac.org/aboutilac.html. [Last accessed on 2011 Dec 11].

[6] NABH guide book to accreditation standards for hospitals. $4^{\text {th }}$ Edn. Dec 2015.

[7] Procedure for quality assurance scheme for basic and composite medical laboratories (entry level). National Accreditation Board for Testing and Calibration Laboratories 128. Available from https://nablindia.org [Last accessed on 2020 March 23]

[8] Guide for preparing quality manual. National Accreditation Board for Testing and Calibration Laboratories 160. Issue no. : 07, issue date: 11-sept-2018 amendment no. : 01, Amendment date: 22-Jul-2019. Available from https://nabl-india.org [Last accessed on 2020 Mar 02].

[9] The Bio-medical waste management rules, 2016. Ministry of environment, forest and climate change, Govt. of India. Gazette of India dated $16^{\text {th }}$ March, 2018.

[10] Application Form for Testing Laboratories. National Accreditation Board for Testing and Calibration Laboratories (NABL) 151. Issue no. : 14, issue date: 25-Jun-2018 amendment no. : 03, Amendment date: 14-Oct-2019. https://nabl-india.org/news and announcement. [Last accessed on 2020 Mar 05].

Citation: Thekkuttuparambil Ananthanarayanan Ajith, " Documentation Required for Accreditation of Medical Testing Laboratories with Special Reference to National Accreditation Board for Testing and Calibration of Laboratories", International Journal of Clinical Chemistry and Laboratory Medicine (IJCCLM), 6(1), pp.6-11, 2020. Available: DOI: http://dx.doi.org/10.20431/2455-7153.0601002

Copyright: () 2020 Authors. This is an open-access article distributed under the terms of the Creative Commons Attribution License, which permits unrestricted use, distribution, and reproduction in any medium, provided the original author and source are credited. 